Provided for non-commercial research and education use. Not for reproduction, distribution or commercial use.

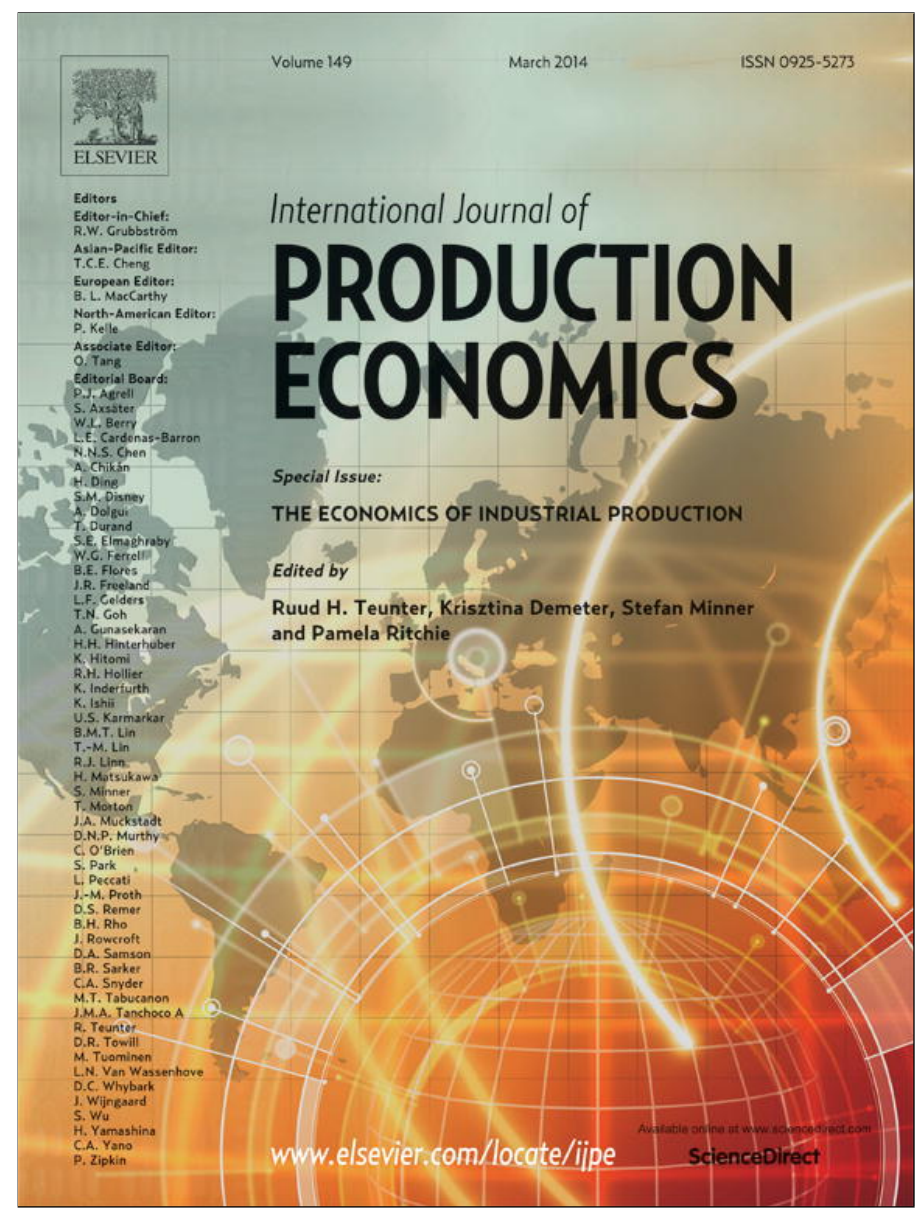

This article appeared in a journal published by Elsevier. The attached copy is furnished to the author for internal non-commercial research and education use, including for instruction at the authors institution and sharing with colleagues.

Other uses, including reproduction and distribution, or selling or licensing copies, or posting to personal, institutional or third party websites are prohibited.

In most cases authors are permitted to post their version of the article (e.g. in Word or Tex form) to their personal website or institutional repository. Authors requiring further information regarding Elsevier's archiving and manuscript policies are encouraged to visit:

http://www.elsevier.com/authorsrights 


\title{
Open innovation: A real option to restore value to the biopharmaceutical R\&D
}

\author{
Giovanna Lo Nigro ${ }^{\mathrm{a}, *}$, Azzurra Morreale ${ }^{\mathrm{a}}$, Gianluca Enea ${ }^{\mathrm{b}}$ \\ ${ }^{a}$ Dept. of Chemical, Management, Mechanical Engineering and Computer Science, University of Palermo, Italy \\ ${ }^{\mathrm{b}}$ Ernst \& Young - Financial \& Business Advisors S.p.a, Milan ( MI ) 20123, Italy
}

\section{A R T I C L E I N F O}

\section{Article history:}

Received 14 April 2012

Accepted 4 February 2013

Available online 18 February 2013

Keywords:

Real options analysis

Licensing

Open innovation

Biopharmaceutical industry

R\&D portfolio

\begin{abstract}
A B S T R A C T
The pharmaceutical landscape has changed, and new business models, based on alliances, are increasingly being adopted in this industry. Biotechnology advances have pushed this development, and pooling complementary resources coming from incumbents and newcomers is a key skill to succeed: these are the premises for a quick spread of the open innovation (OI) paradigm in this industry. R\&D portfolio selection needs R\&D project evaluation, and Real Options Analysis (ROA) is acknowledged as a powerful tool to evaluate uncertain projects that have an intrinsic flexibility. The present research aims to foster the use of ROA in the OI field in order to encourage firms to undertake this innovation model; to achieve this goal the authors propose a closed-form model that is easy to implement, to evaluate the OI initiative for selecting an optimal R\&D portfolio. The study wants to support managers in optimal R\&D portfolio construction in terms of choosing the most promising products, the means by which the related project has to be undertaken (in an open or closed manner; i.e. licensing-in or not) and the self-financing policy. The proposed model can be easily implemented into a spreadsheet, and the inputs needed to run it are usually requested to evaluate projects using the most used net-present-value-based methods. Moreover, some parameters of the model allow strategic aspects to be considered: for example the nature of the project (core/non-core), the impending project phase, and the risk-sharing opportunity.

The results of the developed numerical example show that the selected portfolio is well balanced in terms of development stages, core/non-core therapeutic areas and, licensing-in (an inbound open innovation solution), is preferred in the case of products at their early stages of development.
\end{abstract}

(c) 2013 Elsevier B.V. All rights reserved.

\section{Introduction}

Recent studies find that the pharmaceutical industry has faced a problematic period (2000-2010) resulting in an increase in $R \& D$ investment achieving a $16 \%$ of sales with a $60 \%$ increase on the previous decade. This effort does not match the forecasted returns; nevertheless, big pharmaceutical companies cannot avoid relying on $\mathrm{R} \& \mathrm{D}$, and continue to make it a strong contributor to value creation. Thus, decision-makers should select projects accurately, being sure to choose the most promising, and must consider new paradigm solutions including next-generation licensing and effective precompetitive collaboration with other companies (Dhankhar et al., 2012), without neglecting interdependencies among products and strategic goals. These suggestions imply a proper evaluation of every single project, the

\footnotetext{
*Corresponding author. Tel.: +39 09123861826; fax: + 390917099973.

E-mail addresses: giovanna.lonigro@unipa.it (G. Lo Nigro), azzurra.morreale@unipa.it (A. Morreale), gianlucaenea@gmail.com (G. Enea).
}

enrolment of an open innovation (OI) paradigm in the manager's agenda, and the adoption of a portfolio perspective that is able to incorporate strategic issues into the R\&D decisions.

As a matter of fact, the pharmaceutical industry has experienced an advent in biotech newcomers that foster the OI solutions because of the increasing need for collaboration in order to exploit the complementary resources of incumbents and newcomers: Biotechnology innovation has, in fact, been largely pursued through collaborative arrangements between biotechnology firms (newcomers), who accomplish the discovery and preclinical tests and established pharmaceutical companies (incumbents), which typically undertake clinical trials and marketing (Gupta et al., 2007).

Specifically, the adoption of $\mathrm{OI}$ in the biopharmaceutical industry has been systematically documented by Bianchi et al. (2011), who point out that biopharmaceutical companies enter into relationships with different types of partners (such as large pharmaceutical companies or product biotech firms) to acquire (inbound OI) or to commercially exploit (outbound OI) technologies and knowledge (Chesbrough and Crowther, 2006). 
The governance of these inter-firm relationships can vary from market to hierarchy-like solutions depending on the characteristics of the partners and of the transaction to be completed (Lo Nigro et al., 2012b); at any rate, these agreements represent an operationalization of the OI paradigm in the drugs R\&D field. A key element in the agreements signed between pharmaceutical/ biopharmaceutical and biotechnology companies is flexibility. Real Options Analysis (ROA) is acknowledged as a powerful tool to evaluate uncertain projects that have an intrinsic flexibility (Dixit and Pindyck, 1994; Trigeorgis, 1996). In addition, the pharmaceutical R\&D process has a long and dynamic life, and further investments depend on the success/failure of previous ones, which then also represent an ideal field of application for ROA.

On the other hand, unlike the closed innovation model, the open innovation paradigm highlights the spectrum of alternatives open to firms during the R\&D process; indeed, at any phase of the process, they can decide to start, to continue, to collaborate with others or to abandon the project.

Therefore, as Vanhaverbeke et al. (2008) state, it is surprising that scholars do not pay attention to the existing synergy between ROA and OI. Furthermore, a portfolio perspective is needed to properly allocate the annual budget and to consider the interdependencies among projects. Finally, in order to obtain a balanced portfolio, the objective function has to take into account different aspects, including the possibility of adopting OI solutions to develop each project, as well as a self-financing policy. These considerations underline how important it is for pharmaceutical companies to select a balanced R\&D portfolio, which is composed of products almost on the shelves - i.e. at the latter stages of development - and compounds still in the earlier phases of development.

As illustrated in the next section, the literature fails to deal with these "needs" simultaneously, and managers have highlighted this lack (Hartmann and Hassan, 2006): Our research goal is to fill this literature gap, and to this end we propose a realistic real options model (Open OptFolio Light (OOL)) that is able to support pharmaceutical $R \& D$ decision-makers in the portfolio selection process by suggesting which projects should be undertaken, the best means by which to develop them (through an open- or a closed-innovation paradigm, i.e. licensing-in or not), and the cross-financing policy.

In the following section, a literature analysis will be conducted to highlight the scientific support of our research goal, and the need to fill the aforementioned gap. Section 3 will focus on the biopharmaceutical R\&D project evaluation. The OOL model, which is based on OptFolio (a model available in the literature (Rogers et al., 2002)), is presented in Section 4; in Section 5 OOL is compared to other real options models that are available in the literature to highlight its characteristics, and in Section 6 OOL is applied to a numerical example. In Section 7, conclusions are drawn, the research findings are summarized, and further developments are anticipated.

\section{Literature overview}

Previous research acknowledges ROA as a powerful tool to evaluate biopharmaceutical R\&D investments (Cassimon et al., 2004); nonetheless, the evaluation of a single project would not be consistent with a firm strategy that usually assumes a more comprehensive point of view. In order to overcome this limitation, the whole portfolio of R\&D projects should be considered. This is especially important in the context of the biopharmaceutical industry, which is characterized by very high failure rates of new drug candidates, and by long time to complete the entire $R \& D$ process (Rogers et al., 2002).

Project portfolio selection is crucial in many organizations, which must make decisions on investments, where the appropriate distribution of investments is complex due to varying levels of risk, resource requirements, and interactions among the candidate projects (Berzinsh et al., 2006). In addition, R\&D activities have become increasingly costly and risky; hence, measuring their performance and contribution to value is critical (Lazzarotti et al., 2011). While the portfolio management methods employed in different organizations vary greatly, the objectives that managers are trying to achieve are quite similar (Eilat et al., 2006). According to Cooper et al. (1997), an objective that usually dominates this decision process is that of obtaining a balanced portfolio, i.e. diversifying the projects in the portfolio in terms of various trade-offs such as high risk versus sure bets, internal versus outsourced work, etc. To the best of our knowledge, no model is available in the literature that is able to fulfill this multiple need for balance. This research therefore aims to propose a model that is easy to implement and makes it possible to answer this request.

On the other hand, OI is an incentive to integrate technology management and innovation management (Licthnthaler, 2011), and this reinforces the need to evaluate the entire R\&D project portfolio, rather than simply considering a stand-alone project.

In addition, OI provides an invaluable tool by which to balance an innovation portfolio and share risk; in the meantime, an actively managed portfolio demands judgments calls. The judgments may well be based on quantitative values and careful measurements, but the shadow of false positive and false negative judgment persists (Bingham and Spradlin, 2011) and can be mitigated by adopting an evaluation method that is able to overcome the underrated problem inherent in the net present value-(NPV) -based evaluation method (false negative in the case of flexible alternatives) such as the ROA. Therefore, OI reinforces the usefulness of ROA in this context.

However, organizations, as pointed out by Hartmann and Hassan (2006), while recognizing the importance of the ROA, do not apply it because it is perceived as a complex concept.

The main contribution to the literature of the present research is to propose an ROA model that is easy to implement, in order to support two critical aspects: (i) R\&D projects selection; and (ii) how to carry out the selected projects (internally or externally). Such a tool would represent an operative way to deploy OI. The targeted balance is multifaceted: behind open vs. closed means by which to decline innovation, the equilibrium between products able to produce cash flows and products that need financial sustain is pursued. The model also aims to contribute to the available models, considering the possibility to create a financially balanced portfolio, since it includes a self-financing policy (Enea and Lo Nigro, 2011a) and a tighter control of risk because it includes the option to license the $R \& D$ projects. The resulting model is named Open OptFolio Light (OOL). According to Kamien and Schwartz. (1978), the self-financing of R\&D for a company is urgent for two reasons. First, external financing may be difficult to obtain without substantial related tangible collateral that can be claimed by the lender if the project fails; an R\&D project that fails generally leaves behind few tangible assets of value. Second, the firm might be reluctant to reveal detailed information about the project that would make it attractive to outside lenders, fearing its disclosure to potential rivals.

The output of the model is the composition of the pharmaceutical portfolio, and for each selected drug it is able to suggest whether it should be developed in-house or through an alliance with a biotechnology company, and if (and to what extent) it will finance other projects in the pipeline when it is commercialized. 
The model is also able to deal with variables that take into account the business strategy (the choice of therapeutic areas in which to invest), and characteristics of possible partnership (level of synergy, profit sharing policy, etc.), and it has been tested through a case study taken from the literature (Rogers et al., 2002).

\section{Pharmaceutical R\&D project evaluation}

Discounted cash-flow-based methods, such as NPV, are generally used to evaluate investment projects. However, in the field of $R \& D$ pharmaceutical projects, where high uncertainty and risks (both economic and technical) are prominent, these methods lose a large amount of their effectiveness. In fact, they fail to correctly assess the real value of these projects, which results, among other things, from the flexibility possessed by the management and from the several opportunities these kinds of investments offer.

Thus, the real options approach has received great attention in recent years, because an initial investment in an R\&D project is similar to the purchase of an option on a future investment. On the other hand, a survey conducted by Hartmann and Hassan (2006) into the most important pharmaceutical firms in 2005, which aimed to investigate the methods used by companies in the evaluation of their R\&D projects, finds that ROA use is not very widespread, mainly because of: (i) perceived technique complexity; (ii) lack of acceptance by the decision makers; and (iii) lack of transparency. Our aim is to set up a model that is able to overcome these barriers to ROA adoption.

\subsection{Single pharmaceutical RED project evaluation}

By adopting the Cassimon et al. (2011b) classification for the real options methods, we can address R\&D evaluation projects through ROA in two ways. The former uses numerical methods such as the binomial model (Cox et al., 1979), while the latter evaluates the project using closed-form solutions such as the Black and Scholes (B\&S) formula (Black and Scholes, 1973) and the Geske (1979) model, based on B\&S, which is able to evaluate compound options (a set of subsequent options that are dependent on each other).

Several papers propose different solutions for modeling the multi-phase (bio)pharmaceutical process, and we can classify these according to the chosen method to evaluate the project. So while a first group use a binomial lattice approach, (Kellog and Charnes, 2000; Shockley et al., 2003) or decision tree (Loch and Bode-Greul, 2001), a second group solves this problem with closed-form models. Particularly, as Bowman and Moskowitz (2001) point out, the first application of ROA in the evaluation of a pharmaceutical R\&D project was carried out by Merck, one of the most important pharmaceutical companies, in the early 1990s. Merck adopts the B\&S option-pricing model to determine the option value of an investment project. Since this first attempt, many scholars have devoted their attention to these closed-form solutions, and they refer to more accurate models such as the compound option model (Geske, 1979). Among these, we can mention the two-fold compound approach (Perlitz et al., 1999) or the generalized $n$-fold version of this (Cassimon et al., 2004; Cassimon et al., 2011a). Moreover, in order to more realistically evaluate the pharmaceutical process, several authors adopt "adjusted" formulae based on the B\&S formula (Brach and Paxson, 2001) or on the Geske model (Pennings and Sereno, 2011)

The B\&S formula and Geske model are based on the assumption of a diffusion process (Brownian motion) for the underlying. This implies a continuous arrival of information that changes the underlying value, but in a research environment information tends to arise at discrete points of time. To capture this aspect, several authors propose jump Poisson process models, where discrete value changes are superimposed on the Brownian process (jump-diffusion process) (Merton, 1976; Pennings and Lint, 1997).

Finally, Sereno (2010) applies both a lattice method and a closed-form solution (three-fold compound option) to evaluate a pharmaceutical patent and, as Sereno points out, it is easy to demonstrate that by increasing the number of time steps in the binomial model, the solution converges to the closed-continuous time one for the compound option as well.

Both methods, numerical and closed, have some drawbacks: The numerical methods, which are even more intuitive, cannot be automated and the choice of the number of sub-trees (number of steps) is not a trivial question. The closed-form methods cannot address American put options.

\subsection{Pharmaceutical RED portfolio evaluation}

However, according to several authors, it is better to evaluate the entire R\&D project portfolio of a company instead of its single projects, in order to consider the relations and the interdependencies among them. These interdependencies, which are ignored if projects are evaluated one by one, usually deal with limited resource consumption, risk balancing and company strategies. However, while there is a large amount of literature on pharmaceutical project evaluation using ROA, in practice the method has been used effectively only to evaluate single projects (Copeland and Antikarov, 2001).

A great contribution in this field to scientific literature has been made by Rogers et al. (2002), who developed a stochastic optimization model, called OptFolio, that is able to identify the most valuable projects among the entire R\&D project portfolio of a pharmaceutical company. Starting from this real options optimization model, Rogers and Maranas (2005) proposed an approach by which to select the best licensing strategy for each product in the R\&D portfolio. Specifically, the OptFolio model is based on the binomial tree method. Despite being close to reality, the implementation and use of OptFolio turns out to be very complex and difficult to manage. As a matter of fact, a pharmaceutical company may find it hard to identify an optimal project portfolio to solve a problem with a lot of constraints and several dozen thousands of variables, with only 20 candidate drugs. A step towards simplifying this model was made by Wang and Hwang (2007), who developed a closed fuzzy compound option model to estimate the value of each R\&D project in a pharmaceutical company pipeline. Enea and Lo Nigro (2011a, 2011b) developed an OptFolio Light (OL) model inspired by OptFolio that addresses OptFolio issues in a way that is very easy to implement. So, in order to capture this aspect, Section 5 shows a comparison between OptFolio and OL.

\section{The Open OptFolio Light (OOL) model}

In order to maintain their annual revenues and growth rates, pharmaceutical companies aim to increase both new drugs in the development pipeline and the number of commercial launches each year. Consistently with these goals, they are augmenting their product pipelines by also licensing-in the proprietary compounds by biotechnology companies (Rogers and Maranas, 2005). Licensing-in is a form of inbound OI (Dahlandera and Gannb, 2010), and typically consists of an initial payment, milestone payments based on the successful completion of an R\&D stage, and royalty payments upon product commercialization (Rogers and Maranas, 2005). According to Rogers and Maranas (2005), the pattern of these partnerships is easily assimilated to a real option: So, after an initial up-front payment to the 
biotechnology company, the pharmaceutical company has the right - but not the obligation - to make a milestone payment at each stage of development to continue the alliance.

The aforementioned complexity of OptFolio (see Section 3.2), both in terms of computational load and implementation difficulties, does not increase the likelihood that companies will entrust the optimal selection of their projects to a real optionsbased method. Furthermore, financial interdependencies existing among the projects of a product portfolio have to be underlined. This could mean that selecting a drug to be developed may deduct financial resources from the development of other drugs, and also that it may provide funds to feed the development of new products. In fact, if a drug manages to be commercialized and to achieve satisfactory economic results, a company might use part of its incomes to finance other R\&D projects. This is, as a matter of fact, one of the prominent features of blockbuster drugs.

These considerations highlight the importance for a pharmaceutical company to select a balanced R\&D portfolio, in terms of drugs selected at different stages of development (both drugs in their early stages and successful ones able to provide profits, as well as to finance new drug development), and drugs selected internally (inhouse) or by licensing-in (in alliance with a biotechnology company). Therefore, we propose a closed-form model, Open OptFolio Light (OOL), based on the OL (Enea and Lo Nigro, 2011b), to evaluate OI initiatives to select the optimal R\&D portfolio.

\subsection{Mathematical formulation of $\mathrm{OOL}$}

The model uses the following parameters to describe the problem of portfolio optimization projects:

$i=1,2, \ldots, M$ products/drugs/molecules (in the following drugs) $s=1,2, \ldots, S$ stage of the process of drug development

$t=0,1, \ldots T$ year of the portfolio planning horizon

For each of the candidate drugs, as also suggested by the OptFolio model, the impending stage at the present time $t=0$ is classified as $s=1$, regardless of where the candidate drug is in its development. Subsequent development stages are numbered in ascending order until termination at product launch. Let us also define:

$V_{0 i} \quad$ NPV of cash flows for drug $i$ after FDA approval

$\sigma_{i} \quad$ estimated annual market volatility for drug $i$

$r \quad$ risk-free interest rate

$T_{i s} \quad$ length in years of stage $s$ of drug development for drug $i$

$I_{i s} \quad$ investment cost of developmental stage $s$ for drug $i$

$\phi_{i s} \quad$ probability of technical success in stage $s$ of development for drug $i$

$B_{t} \quad$ budgetary constraint for year $t$

$C_{i} \quad$ value of drug $i$ if it is developed in house

$C_{i}^{\prime} \quad$ value of drug $i$ if it is developed in alliance with a biotech company

$F_{i} \quad$ annual cash flow of drug $i$ developed in house

$F_{i}^{\prime} \quad$ annual cash flow of drug $i$ developed in alliance

$r_{p h} \quad$ rate of return in the pharmaceutical industry

$n \quad$ drugs commercial life

$X_{i}^{R \& D} \quad$ percentage of cash flows of drug $i$, developed in house, invested in $R \& D$

$X_{i}^{\prime R \& D} \quad$ percentage of cash flows of drug $i$, developed in alliance, invested in $\mathrm{R} \& \mathrm{D}$

$V_{0 i}$ represents the estimated value of drug $i$, based on the NPV of all cash flows that result if the drug is commercialized when it has just passed the last phase (FDA) of its development process.
This value is an aggregate of the projected sales revenue of the drug minus production, distribution, and marketing costs and all other expenses (Rogers et al., 2002). The market volatility $\sigma_{i}$ is the standard deviation of $V_{0 i}$, which is usually estimated using historical sales data of similar products. The risk-free interest rate, $r$, corresponds generally with an observable market rate, such as US Treasury Bills. Every development stage $s$ of each candidate drug $i$ could have a different length $T_{i s}$, investment cost to be carried out $I_{i s}$, and probability of technical success $\phi_{i s}$. The budgetary constraint $B_{t}$ is the total amount of financial resources that a company can spend for its R\&D projects in the year $t$.

The drug value $C_{i}$ may be calculated by different expressions depending on the number of phases left. B\&S formula can be used if a drug has only two development phases left and presents the following expression:

$C_{i}=V_{0 i} \times e^{-r t} \times N\left(d_{1 i}\right)-I_{i 2} \times e^{-r\left(t_{i 1}^{*}-t\right)} \times N\left(d_{2 i}\right)$

with:

$d_{1 i}=\frac{\ln \left(V_{0 i} /\left(I_{i 2} \times e^{-r\left(t_{i 1}{ }^{*}-t\right)}\right)\right)}{\sigma_{i} \times \sqrt{\left(t_{i 1}{ }^{*}-t\right)}}+\frac{\sigma_{i} \times \sqrt{\left(t_{i 1}{ }^{*}-t\right)}}{2}$

$d_{2 i}=d_{1 i}-\sigma_{i} \times \sqrt{\left(t_{i 1}{ }^{*}-t\right)}$

where: $t_{1 i}^{*}$ is the time to maturity of the call option $C_{i}, t$ is the current time, and $N$ is the cumulative normal distribution function.

On the other hand, Geske's formula should be used when a drug has to pass through more than two phases before being commercialized. If there are only three development phases left, the traditional Geske formula can be used:

$$
\begin{aligned}
C_{i}= & V_{0 i} \times e^{-r t} \times N_{2}\left(a_{1 i}, a_{2 i} ; \rho_{i}\right)-I_{i 3} \times e^{-r\left(t_{i 2}-t\right)} \times N_{2}\left(b_{1 i}, b_{2 i} ; \rho_{i}\right)-I_{i 2} \\
& \times e^{-r\left(t_{i 1}-t\right)} \times N\left(b_{2 i}\right)
\end{aligned}
$$

with

$b_{1 i}=\frac{\ln \left(V_{0 i} / \bar{V}_{i}\right)+\left(r-\left(\sigma_{i}^{2} / 2\right)\right) \times\left(t_{i 1}-t\right)}{\sigma_{i} \times \sqrt{\left(t_{i 1}-t\right)}}$

$b_{2 i}=\frac{\ln \left(V_{0 i} / I_{i 3}\right)+\left(r-\left(\sigma_{i}^{2} / 2\right)\right) \times\left(t_{i 2}-t\right)}{\sigma_{i} \times \sqrt{\left(t_{i 2}-t\right)}}$

$a_{1 i}=b_{1 i}+\sigma_{i} \times \sqrt{\left(t_{i 1}-t\right)}$

$a_{2 i}=b_{2 i}+\sigma_{i} \times \sqrt{\left(t_{i 2}-t\right)}$

$\rho_{i}=\sqrt{\left(t_{i 1}-t\right) /\left(t_{i 2}-t\right)}$

where: $t_{i 1}$ is the time to maturity of the compound option $C_{i}, t_{i 2}$ is the time to maturity of the underlying call option, and $\bar{V}_{i}$ is the solution of

$C_{i}\left(V_{i}, t_{i 1}\right)-I_{i 2}=0$

where $N_{2}$ is the bi-variate cumulative normal distribution function with $a_{1 i}\left(b_{1 i}\right)$ and $a_{2 i}\left(b_{2 i}\right)$ as upper and lower limits and $\rho_{i}$ as the correlation coefficient between the two variables.

For drugs with more than three phases left, the aforementioned extended Geske model, developed by Cassimon et al. (2004), is necessary. However, in order to simplify the analysis, for example in a spreadsheet where an $n$-variate cumulative normal distribution is hard to implement, the traditional Geske expression can be used. To do this if a drug with four phases left is considered, $s=2$ and $s=3$ stages, for instance, could be merged if the decision to undertake both of them is made at the beginning of the $s=2$ stage. This allows the drug to appear as it has only three stages left instead of four. The investment/exercise price of 
this new single stage can be calculated as

$I_{i 2,3}=I_{i 2}+I_{i 3} \times e^{-r T_{i 2}}$

In our model $t=0$ from Eqs. (1)-(9).

Finally, for drugs in the approval stage, i.e., with only one phase left, the traditional NPV is used.

Moreover, as suggested by Rogers and Maranas (2005), a biotech company will grant the license to a pharmaceutical company if the alliance alternative offers a value that is at least equal to the one obtained if the biotech develops the drug on its own. So, it is necessary to introduce the concept of indifference for the biotech company, at time $t=0$, in order to obtain the licensing conditions: payments and royalties.

$C_{i}($ Biotech $)$ license $+P_{i 1}-I_{i 1}=C_{i}($ Biotech $)$ nolicense $-I_{i 1}$

Actually, the biotech R\&D process can be modeled in the same way as the pharma one, so we can adopt ROA to evaluate it: In literature the biotech alternatives are assessed using NPV (Lo Nigro et al., 2012a; Rogers and Maranas, 2005).

The terms $C_{i}$ (Biotech)nolicense and $C_{i}$ (Biotech)license, are calculated using the formulae mentioned above (B\&S/Geske/NPV). In particular, the underlying asset value, i.e. the net present value of project expected incomes, in $C_{i}$ (Biotech)nolicense is $V_{0 i} \times \gamma_{i}^{\prime}$, where the initial value of the drug is multiplied by the amplification factor $\gamma_{i}^{\prime}$, which takes into account the possible added value from the biotech firm. On the other hand, if the biotech company will license the drug, the underlying asset becomes $V_{0 i} \times \gamma_{i} \times\left(1-\alpha_{i}\right)$ (see Table 1). In fact, if the biotech company signs the agreement with the pharmaceutical company, the pharma will transfer an upfront payment $\left(P_{i 1}\right)$, interim payments $\left(P_{i s, s \neq 1}\right)$ and a percentage of the revenues $\left(1-\alpha_{i}\right)$ to the bio-company. The amplification factor $\gamma_{i}$, which is greater than $\gamma_{i}^{\prime}$, represents the measure of value added to the project by the bio-pharmaceutical alliance (the NPV of the alliance future incomes becomes $V_{0 i} \times \gamma_{i}$ ). A large pharmaceutical company, which has advanced marketing resources, is able to double the value that would generate a small biotech company for a drug license (Rogers and Maranas, 2005). According to Nicholson et al. (2005), if an experienced pharmaceutical firm works with a biotech company, some of the development costs will be lower or expected revenues will be higher (and this causes an increasing drug value). Moreover, the exercise price, that is the current value of project investment cost, considered in $C_{i}$ (Biotech)license, will not be the whole investment cost of developmental stage $s$ for drug $i\left(I_{i s}\right)$, but a lower value: stage by stage biotech company will invest $\left(I_{i s}-P_{i s}\right)$ (see Table 1), with $P_{i s} \leq I_{i s}, \forall i$, s.

In particular, we impose among the payments the same proportionality of the corresponding investments. We refer to the "hedging investment policy" (Rogers and Maranas, 2005), which consists of smaller up-front payments and larger milestone payments in later stages of development. Imposing the indifference condition we obtain, for each $i$, a value of $\alpha_{i}$ and the corresponding payment $P_{i 1}$ (the other payments are functions of $P_{i 1}$ ), that satisfy Eq. (12): In fact, the problem admits $\infty^{1}$ solutions.

Moreover, the model includes four dichotomous variables, two for drugs developed in house $\left(H_{i}\right.$ and $\left.h_{i}\right)$, and two for drugs

Table 1

Input variables used in biotech real options evaluation.

\begin{tabular}{lll}
\hline Variable & $C_{i}$ (Biotech)nolicense & $C_{i}$ (Biotech)license \\
\hline Underlying asset value & $V_{0 i} \times \gamma_{i}^{\prime}$ & $V_{0 i} \times \gamma_{i} \times\left(1-\alpha_{i}\right)$ \\
Exercise price & $I_{i s}$ & $I_{i s}-P_{i s}$ \\
\hline
\end{tabular}

developed in alliance $\left(L_{i}\right.$ and $l_{i}$ ), with the following meanings: $H_{i}\left(L_{i}\right)= \begin{cases}1 & \text { if the drug is selected for the optimal portfolio } \\ 0 & \text { otherwise }\end{cases}$ $h_{i}\left(l_{i}\right)=\left\{\begin{array}{l}1 \text { if part of the cash flows of the drug is reinvented } \\ 0\end{array}\right.$

Clearly, if a drug is developed in-house by the pharmaceutical company, it cannot be licenced-in. Mathematically, this condition can be expressed with the following constraint, which also considers the possibility that the same drug is not selected:

$H_{i}+L_{i} \leq 1 \quad \forall i$

As mentioned before, further assumptions are needed to achieve a balanced R\&D portfolio. The first, which concerns the annual revenue distribution of a marketed product, assumes that, after its commercialization, a drug provides a company with uniform cash flows, $F_{i}$, for $n$ years. The value of these annual incomes for drug $i$, developed in-house, is:

$F_{i}=V_{0 i} \times \frac{\left(1+r_{p h}\right)^{n} \times r_{p h}}{\left(1+r_{p h}\right)^{n}-1}$

If, however, the drug is developed within the alliance, the value of the cash flow turns out to be:

$F_{i}^{\prime}=V_{0 i} \times \gamma_{i} \times \alpha_{i} \times \frac{\left(1+r_{p h}^{\prime}\right)^{n} \times r_{p h}^{\prime}}{\left(1+r_{p h}^{\prime}\right)^{n}-1}$

More precisely, we assume that $r_{p h}^{\prime}$ is less than $r_{p h}$ because of the risk sharing coming from the agreement. In order to consider the possibility of reinvesting the cash flow of a drug, other constraints are needed. The self-financing by the commercialized drugs is allowed only if the drug has been selected to be part of the optimal portfolio. In mathematical terms, these concepts can be expressed with the following constraints:

$h_{i} \leq H_{i} \quad \forall i$

$l_{i} \leq L_{i} \quad \forall i$

However, only a share $X_{i}^{R \& D}$ or $X_{i}^{\prime R \& D}$ (depending on the adoption of a closed rather than open paradigm, respectively) of annual cash flow is potentially reinvested to fund the development of further drugs. Thus, the actual amount of financial resources, deriving from the commercialization of drug $i$ and planned to be invested yearly in R\&D, is:

$R F_{i}=X_{i}^{R \& D} \times F_{i}$ if drug $i$ is developed in house

$R F_{i}^{\prime}=X_{i}^{\prime R \& D} \times F_{i}^{\prime}$ if drug $i$ is developed in alliance

$0 \leq X_{i}^{R \& D}$ and $X_{i}^{\prime R \& D} \leq 1$

The resulting mathematical model is as follows:

$$
\begin{aligned}
\max R O V & =\sum_{i}\left(C_{i}^{\prime}-P_{i 1}\right) \times L_{i}+\sum_{i}\left(C_{i}-I_{i 1}\right) \times H_{i}-\sum_{i, t} \frac{\omega_{i t} \times R F_{i}^{\prime}}{\left(1+r_{p h}^{\prime}\right)^{t}} \\
& \times l_{i}-\sum_{i, t} \frac{\omega_{i t} R F_{i}}{\left(1+r_{p h}\right)^{t}} \times h_{i}
\end{aligned}
$$

s.t.:

$\sum_{i, s}\left(P_{i s} \phi_{i, s-1} w_{i s t}\right) \times L_{i}+\sum_{i, s}\left(I_{i s} \times \phi_{i, s-1} w_{i s t}\right)$

$\times H_{i} \leq B_{t}+\sum_{i}\left(\omega_{i t} \times R F_{i}^{\prime}\right) \times l_{i}+\sum_{i}\left(\omega_{i t} R F_{i}\right) \times h_{i} \forall t$

constraints of Eqs. (13)-(20).

with: $H_{i}, L_{i}, h_{i}, l_{i} \in[0,1]$ 
where the binary parameter $\omega_{i t}$ allows the contribution of drug $i$ in the period $t$ to be considered only if the drug has already been introduced to the market in that period.

$C_{i}$ (the drug value without alliance) is calculated using the above formulae (B\&S/Geske/NPV and, in the case of real options, the exercise price, for each stage, $s$, and the underlying asset for each drug, $i$, will be, respectively, $I_{i s, s \neq 1}$ and $V_{0 i}$ ). On the other hand, in the case of real options $C_{i}^{\prime}$, the exercise price and the underlying asset will be $P_{i s, s \neq 1}$ and $V_{0 i} \times \gamma_{i} \times \alpha_{i}$, respectively. The objective function (Eq. (21)) can be decomposed into two parts: the first concerns the selection of a drug candidate to be included in the optimal portfolio (considering the possibility of developing it through an alliance with the biotech firm), and the second concerning the possibility of using part of the income of a selected drug to fund additional R\&D projects. According to Perlitz et al. (1999), accounting for today's investment for each drug $i, I_{i 1}$ or $P_{i 1}$, is a sunk cost and does not affect the option value, but decreases the total project value; indeed, successive investments/ payments affect the real options value and do not appear explicitly in the objective function.

As far as the budget constraint (Eq. (22)) is concerned, the first part of the equation is related to the expenses necessary for the development of drugs, while the second part includes the financial contributions brought to R\&D by those commercialized drugs whose revenues have been partially allocated for this specific purpose. The binary parameter $w_{\text {ist }}$ appears, finally, in the OptFolio model too, and makes it possible to include in budgetary constraints only those drugs (i) beginning a stage of development $(s)$ in the period $(t)$ (a phase can be longer than one year).

The mathematical formulation above can be simplified; for example, some binary variables can be omitted if, a priori, their value is known (products in the earlier phases of development cannot finance other products in the time horizon considered).

\section{OptFolio and OL: A comparison}

The aim of OptFolio (Rogers et al., 2002) and OL (Enea and Lo Nigro (2011a, 2011b) is to determine the optimal drug developmental portfolio that maximizes the real options value (ROV), which is the overall value of the portfolio given a set of candidate drugs in various stages of development. To estimate the value of the single project/drug, OptFolio uses a quadranomial approach (a two-variable binomial tree) and models each project development as a series of continuation/abandonment options, deciding at each phase whether to proceed further or stop the development (Rogers et al., 2002). However, according to Copeland and Antikarov (2001) and Cassimon et al. (2004), decision tree methods can easily become difficult to manage because of the rapidly increasing number of trees with the size of the portfolio. Another problem is represented by the discounted rate (Trigeorgis, 1996): although different rates at different stages in the drug development process could be used, decision tree analysis does not tell us exactly how this should be done.

Actually, binomial approaches show a somewhat misleading intuitive simplicity because they still use a numerical method, which is inferior to closed-form models (Chance, 1998), such as the Geske model. According to Cassimon et al. (2004, 2011a), two problems may arise by adopting binomial approaches. The first problem is that it is not known how many time steps are necessary in order to obtain an accurate option price. In general, binomial prices converge to an analytical result. However, theory does not say how many periods are needed to obtain a good level of accuracy (Cassimon et al., 2004, p. 49). The second problem is the choice of the up $(u)$ and down ratios $(d)$ and the risk of neutral probabilities, which are used in the OptFolio model and computed using the formulae for pricing stock options based on the binomial model provided by Cox et al. (1979). Chriss (1997, p. 238) demonstrates that, under certain conditions (under given input parameters), the Cox, Ross and Rubenstein binomial tree does not work.

Moreover, the resulting OptFolio formulation, as pointed out by the same authors, involves a large number of binary variables and causes the objective function to no longer be a linear function. Thus, in order to achieve a more tractable approach in a linear form, they must solve a sub-problem with no budgetary restrictions. This linearization procedure reduces the variables number, but complicates the global problem resolution. Several constraints are present in the model, such as budgetary constraints or others that are used to enforce the precedence between the different development phases of a drug and to prevent a drug which has been abandoned in an earlier stage from being selected. Using this approach, the mathematical model for the case study considered (the same presented in Section 6) includes 893 binary variables and 12,843 continuous variables.

To reduce OptFolio's complexity, OL introduces some alterations, while the goal is the same. The first is the way in which the R\&D process is modeled: OL opts for closed-form formulae instead of the binomial method, making the computational burden lighter. Particularly, the B\&S formula is used for candidate drugs which are about to complete their R\&D processes and have only two development phases left, while the Geske formula is used for candidate drugs in earlier phases of their development. Lastly, if a drug has only one phase left to pass through, which is generally the approval phase, the NPV can be adopted. As a consequence, an important difference from the OptFolio model is that the real options drug values are, in our mathematical model, input parameters, while in OptFolio they are an output of the mathematical programming (they are considered in the objective function). This is an important issue because it greatly reduces the implementation complexity.

On the other hand, the main limit of B\&S is its inability to solve the American put option; in OL the R\&D process is seen as a sequence of the American call options, so this limitation does not apply.

Another limitation is represented by the assumed distribution for the underlying: in B\&S formula this is Brownian Motion (Black and Scholes, 1973). This particular motion implies a continuous arrival of information that changes the underlying value (Pennings and Lint, 1997). However, information that affects the underlying value (the NPV of future cash flow) arrives at discrete points of time and this means that the managers, in real markets, do not continuously adjust the underlying value, but rather do so only when information with strategic impact arrives (Pennings and Lint, 1997).

In addition, for drugs that are in early phases of their development, OL is based on Perlitz et al.'s (1999) approach, which models the complex R\&D process in two phases (Eq. (11)). This simplification is addressed to keep the mathematics as simple as possible, because in this way the two-period compound option model of Geske (1979) can be used. Using a generalization of Geske's compound options Cassimon et al. (2004) derive a closedform solution for the $n$-fold compound option model. However, this model, while being a better fit for the pharmaceutical process than the model of Perlitz et al. (1999), is more complicated from a mathematical point of view. In addition, Cassimon et al. (2011a) present a valuation of a project (Vitosha project) using both the two-fold compound option approach and the $n$-fold compound option approach: the results do not seem to be very different.

Moreover, OL foresees, inside the closed solution, the possibility to further or stop investments (Perlitz et al., 1999) during the pharmaceutical R\&D if the outcome of any phase is or not 
satisfactory(indeed, in this case, the corresponding single real options value becomes negative). On the other hand, a drug can be dismissed because of budgetary constraints. These two assumptions allow OL to use a binary variable for each drug, with only one subscript to model whether a drug is selected to be part of the optimal portfolio. In this mode, we can solve the same case study (Rogers et al., 2002) with only 40 binary variables and 20 continuous variables.

Table 2 summarizes the similarities, key assumptions, weaknesses and strengths of OptFolio and OL.

\subsection{OOL: A comprehensive comparison}

From the practitioner point of view, OOL is also able to include the closed/open innovation alternative for each drug, and to take into account the self-financing policy. While there is a large amount of literature on single pharmaceutical project evaluation using ROA, few models have been developed that consider pharmaceutical portfolio management. To the best of our knowledge, three models (Rogers et al., 2002; Rogers and Maranas, 2005; Wang and Hwang, 2007) are available to select the optimal portfolio. Particularly, the models of Rogers et al. (2002) and Wang and Hwang (2007) adopt the same case study (Rogers et al. 2002) we use to test OOL. Therefore, it is interesting to show a comparison between these models to understand how OOL differs from them, and the unique features that make OOL more attractive. While the former, the OptFolio model (Rogers et al., 2002), has been thoroughly described in Section 5, the second (Wang and Hwang, 2007) is a fuzzy compound option model to estimate the value of each R\&D project. Specifically, the authors adopt a fuzzy real options valuation method that is based on the method proposed by Carlsson and Fullér (2003). They use the Geske compound options valuation model for all 20 drugs, but we believe that the method (Geske, B\&S, or simple NPV) should depend on the remaining phases. Moreover, the authors formulate the R\&D portfolio selection problem as a fuzzy zero-one integer programming model with the aim of maximizing an objective function, subject to budgetary constraints or constraints on the availability of human resources and other mathematical constraints. Specifically, the objective function is the total ROV (fuzzy real option value) of selected projects, minus all development costs in the planning horizon.

However, according to Hassanzadeh et al. (2011), deducting the total development costs of selected projects from their ROVs in the objective function implies that the total benefit of the portfolio is doubly affected (because they are also considered as exercise prices in the real options evaluation) by development costs (except for the initial cost).
Moreover, neither of the above models considers two aspects that we see as very important in terms of a balanced portfolio: i) the self-financing option and ii) the decision to license-in or to internally develop selected projects. Finally, our model has been tested using a spreadsheet (as described in the following section), so it can be implemented and used in a simple way; this characteristic could bring managers to adopt an ROA-based tool.

\section{An OOL numerical example}

The low computational burden of OOL allows its implementation in a Microsoft Excel spreadsheet. Any pharmaceutical company interested in evaluating and selecting its R\&D projects could create its own optimal products portfolio simply by entering the drug information and clicking a button. Specifically, the model requires inputs regarding budget limitations as well as candidate drugs, such as their expected current values, volatilities, technical success rates and investment costs for each stage and type, which indicates what the impending development stage of a drug is at the time of portfolio selection. Thus, the spreadsheet identifies whether the B\&S, Geske or NPV approach is needed for each drug, and eventually calculates the options parameters, which are useful for estimating the real options values $C_{i}$ (Enea and Lo Nigro, 2011a) and $C_{i}^{\prime}$. Ultimately, it is sufficient to click on a macro button, which launches the Excel solver to find the balanced optimal portfolio composition. Of course, if the drug is developed jointly through an alliance with a biotech company, among the input parameters the payments that the pharmaceutical company will pour into the biotech company during the agreement will substitute the investments. To calculate payments and royalties by the above indifference condition (Eq. (12)), it is therefore necessary to introduce additional input parameters such as the values of $\gamma_{i}$ and $\gamma_{i}^{\prime}$, as shown in Fig. 1 .

As an illustrative example of the model OOL, we use the case study presented by Rogers et al. (2002), which concerns the portfolio selection of a pharmaceutical company with 20 drug candidates $(M)$ for an R\&D portfolio. Each of them is classified into six categories, depending on which stage of development it is at (Table 3 ).

In particular, drugs of type 1, 2, 3 and 4 are all placed in the clinical phase, which is divided into three sub-phases (phase I, phase II, phase III). Moreover, drugs of type 5 and 6 have only the commercialization phase (or phase IV) left.

The length of phases I and II have been assumed to be equal to one year each, while the length of phase III and FDA approval is equal to two years each, resulting in an overall length of six years for the R\&D process. Budget limitations have been considered as $\mathrm{M} \$ 400$ for the first year and $\mathrm{M} \$ 800$ for the remainder, with a

Table 2

A comparison between OptFolio and OptFolio Light.

\begin{tabular}{|c|c|c|}
\hline & OptFolio & OptFolio Light \\
\hline $\begin{array}{l}\text { Similarities } \\
\text { - Goal } \\
\text { - Financial option used } \\
\text { - Portfolio optimiziation tool }\end{array}$ & $\begin{array}{l}\text { Pharmaceutical R\&D portfolio optimization } \\
\text { Call option } \\
\text { Mathematical programming formulation }\end{array}$ & $\begin{array}{l}\text { Pharmaceutical R\&D portfolio optimization } \\
\text { Call option } \\
\text { Mathematical programming formulation }\end{array}$ \\
\hline $\begin{array}{l}\text { Key assumptions } \\
\text { - Real options model } \\
\text { - Means of contemplation }\end{array}$ & $\begin{array}{l}\text { Quadranomial approach } \\
\text { Discrete }\end{array}$ & $\begin{array}{l}\text { Closed formulae (B\&S/Geske); NPV } \\
\text { Continuous }\end{array}$ \\
\hline Weaknesses & $\begin{array}{l}\text { Huge number of variables and constraints } \\
\text { Arbitrary granularity (number of sub-trees) }\end{array}$ & $\begin{array}{l}\text { Not applicable in the case of American put } \\
\text { Continuous change in the underlying value due to Brownian motion }\end{array}$ \\
\hline Strengths & Transparency of the binomial tree approach & $\begin{array}{l}\text { Easy implementation } \\
\text { Flexibility (possibility to take into account open innovation and self-financing) }\end{array}$ \\
\hline
\end{tabular}




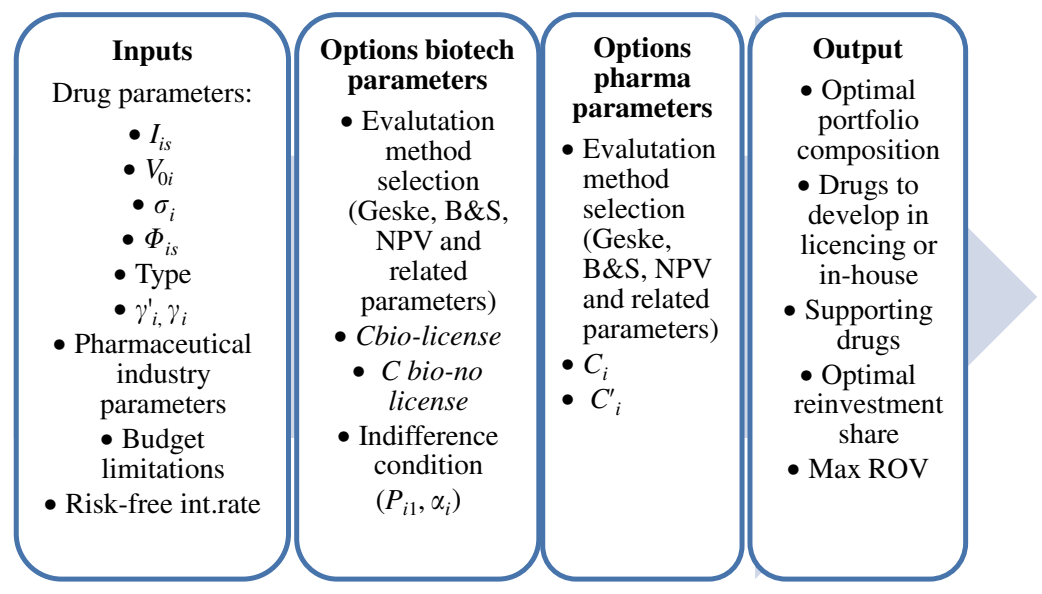

Fig. 1. Optimal portfolio selection process using the new model spreadsheet.

Table 3

Candidate drugs.

\begin{tabular}{|c|c|c|c|c|}
\hline Type & $\begin{array}{l}\text { Beginning } \\
\text { phase }\end{array}$ & $\begin{array}{l}\text { Candidate drugs } \\
(M)\end{array}$ & $\begin{array}{l}\text { Evaluation } \\
\text { method }\end{array}$ & $\begin{array}{l}\text { Development } \\
\text { stages left }\end{array}$ \\
\hline 1 & Phase I & $1,2,3,4,5,6$ & Geske & 4 \\
\hline 2 & Phase II & $7,8,9,10,11$ & Geske & 3 \\
\hline 3 & Phase III & $12,13,14$ & $B \& S$ & 2 \\
\hline 4 & $\begin{array}{l}2^{\text {nd }} \text { year } \\
\text { Phase III }\end{array}$ & 15,16 & $B \& S$ & 2 \\
\hline 5 & $\begin{array}{l}1^{\text {st }} \text { FDA } \\
\text { Approval }\end{array}$ & 17,18 & NPV & 1 \\
\hline 6 & $\begin{array}{l}2^{\text {nd }} \text { FDA } \\
\text { Approval }\end{array}$ & 19,20 & NPV & 1 \\
\hline
\end{tabular}

planning horizon of five years (Rogers et al., 2002). In order to obtain from the $V_{0 i}$ the annual cash flow $F_{i}\left(F_{i}^{\prime}\right)$ which represents the available self-financing from the commercialized drugs developed, a value of $r_{p h}$ equal to $12 \%$ was also assumed, as suggested by DiMasi et al. (2003), along with a lower value for $r_{p h}^{\prime}$ (due to the risk sharing) equal to $11 \%$.

Finally, the risk-free interest rate, $r$, has been set at $5 \%$. This corresponds to an average observable market rate (e.g., US Treasury Bills, as used by Rogers et al., 2002), which we adopted to compare part of the numerical example results. In addition, the life of a drug after its commercialization, $n$, has been considered as equal to 10 years, since after this lapse of time a drug normally loses its patent protection, causing its annual incomes to fall dramatically.

Some of the input parameters (Table 4) of the model, such as the present value of future cash flows of drugs, the probability of technical success, investments for each drug, and volatility, have been estimated based on historical and industry data (Rogers et al., 2002), and the biotech input parameters are supposed as equal to the pharmaceutical ones.

Among the input parameters, some reflect the pharmaceutical strategy and the agreement characteristics $\left(P_{i s=1,4}, \alpha_{i}, \gamma_{i}, \gamma_{i}^{\prime}\right.$, the therapeutic area); these are summarized in Table 5 (Ncore refers to a non-core therapeutic area). Moreover, for the sake of clarity, Table 5 also shows the drug values $\left(C_{i}\right.$ and $\left.C_{i}^{\prime}\right)$. Finally, for drugs 17-20, which are in the FDA phase, possible alliance with a biotech company is not considered.

The therapeutic area (core or non-core) influences the choice of factor $\gamma_{i}^{\prime}$, which considers the possible added value from the biotech company to the value of the drug produced by the pharmaceutical company. As can be observed from Table 5, higher values are assumed for the drugs allocated in the early stages of the process, in which the biotech enterprise has more expertise than the pharmaceutical company. More precisely, as suggested by empirical analysis on the adoption of open innovation in the biopharmaceutical industry (Bianchi et al., 2011), a larger value of $\gamma_{i}^{\prime}$ is assumed for a drug placed in a non-core area, whereby the biotech firm is supposed to have more specialized competencies than the pharmaceutical industry, thus increasing the value of the project. This explains the high value for $\gamma_{i}$, which is value added from collaboration within the project, which, for some drugs, equates to double the amount achieved without collaboration.

Bounded by a specific budget for the R\&D process, the pharmaceutical company has to decide which drugs should be allocated development finance in later years. The same budget limitations and values of other common input parameters used in the aforementioned case study (Rogers et al., 2002) have been considered.

\subsection{Analysis of results}

In order to compare our model to the OptFolio model (Rogers et al., 2002), which represents our benchmark, we can simplify OOL by neglecting the license possibility: in this way, OOL becomes OL (Enea and Lo Nigro, 2011b) and gives the same output typologies as the benchmark model.

Table 6 shows a comparison of the optimal portfolio selected by the OptFolio model and that selected by the OL model, referring to the same case study (Rogers et al., 2002) as mentioned above.

It is clear from the above that the proposed OL model suggests selecting as many as nine drugs, unlike the original OptFolio which selected only the two that were closest to commercialization. In fact, it replaces drug 20 with eight products that less profitable at the decision time, but which have greater growth opportunities (drug 19 excepted).

Table 7 shows the optimal portfolio selected, ceteris paribus, in the case of open innovation (alliances are considered, so we refer to the OOL model).

In general, drugs that have reached the last stage of the development process have a higher value, as their market launch is more likely. However, investment and marketing costs associated with their launch are significant, and limit the number of products that pharmaceutical companies can bring to market. The size of the optimal portfolio therefore balances the desire to launch drugs that are most valuable and that are in the FDA approval phase, with investments into drugs that are potentially valuable in the early stages of the development process. The 
Table 4

\begin{tabular}{|c|c|c|c|c|c|c|c|c|c|c|c|}
\hline M & Type & $V_{0 i}$ & $\sigma_{i}(\%)$ & $\phi_{i 1}$ & $\phi_{i 2}$ & $\phi_{i 3}$ & $\phi_{i 4}$ & $I_{i 1}(\mathrm{MS})$ & $I_{i 2}(\mathrm{MS})$ & $I_{i 3}(\mathrm{MS})$ & $I_{i 4}(\mathbf{M S})$ \\
\hline 1 & 1 & 50 & 80 & 0.6 & 0.7 & 0.8 & 0.95 & 2 & 10 & 20 & 30 \\
\hline 2 & 1 & 100 & 70 & 0.65 & 0.55 & 0.75 & 0.90 & 3 & 10 & 40 & 45 \\
\hline 3 & 1 & 200 & 50 & 0.7 & 0.8 & 0.9 & 0.90 & 10 & 15 & 60 & 100 \\
\hline 4 & 1 & 200 & 60 & 0.5 & 0.7 & 0.8 & 0.90 & 5 & 15 & 50 & 170 \\
\hline 5 & 1 & 600 & 50 & 0.6 & 0.6 & 0.7 & 0.90 & 20 & 40 & 45 & 200 \\
\hline 6 & 1 & 100 & 20 & 0.85 & 0.9 & 0.9 & 0.95 & 15 & 15 & 25 & 45 \\
\hline 7 & 2 & 80 & 50 & 0.6 & 0.8 & 0.95 & - & 10 & 25 & 30 & - \\
\hline 8 & 2 & 100 & 70 & 0.6 & 0.8 & 0.95 & - & 20 & 35 & 50 & - \\
\hline 9 & 2 & 180 & 55 & 0.75 & 0.7 & 0.85 & - & 20 & 55 & 80 & - \\
\hline 10 & 2 & 380 & 35 & 0.6 & 0.8 & 0.95 & - & 30 & 55 & 120 & - \\
\hline 11 & 2 & 80 & 45 & 0.6 & 0.8 & 0.95 & - & 10 & 25 & 30 & - \\
\hline 12 & 3 & 100 & 80 & 0.8 & 0.9 & - & - & 30 & 60 & - & - \\
\hline 13 & 3 & 400 & 30 & 0.8 & 0.9 & - & - & 75 & 180 & - & - \\
\hline 14 & 3 & 700 & 40 & 0.6 & 0.85 & - & - & 90 & 280 & - & - \\
\hline 15 & 4 & 500 & 35 & 0.8 & 0.95 & - & - & 50 & 100 & - & - \\
\hline 16 & 4 & 300 & 100 & 0.7 & 0.9 & - & - & 80 & 150 & - & - \\
\hline 17 & 5 & 350 & 60 & 0.75 & - & - & - & 180 & - & - & - \\
\hline 18 & 5 & 550 & 30 & 0.9 & - & - & - & 220 & - & - & - \\
\hline 19 & 6 & 800 & 60 & 0.7 & - & - & - & 250 & - & - & - \\
\hline 20 & 6 & 1150 & 20 & 0.9 & - & - & - & 350 & - & - & - \\
\hline
\end{tabular}

Table 5

Strategic input parameters and real options values of drugs.

\begin{tabular}{|c|c|c|c|c|c|c|c|c|c|c|}
\hline M & $\alpha_{i}$ & $\gamma_{i}^{\prime}$ & $\gamma_{i}$ & Ther. area & $C_{i}$ & $C_{i}^{\prime}$ & $P_{i 1}$ (MS) & $P_{i 2}$ (MS) & $P_{i 3}$ (MS) & $P_{i 4}(\mathrm{MS})$ \\
\hline 1 & 0.541 & 1.5 & 2 & Ncore & 16.978 & 25.050 & 1.523 & 7.616 & 15.232 & 22.848 \\
\hline 2 & 0.539 & 1.5 & 2 & Ncore & 37.559 & 52.308 & 2.432 & 8.108 & 32.433 & 36.487 \\
\hline 3 & 0.477 & 1.3 & 1.8 & Core & 69.371 & 99.237 & 5.041 & 7.561 & 30.247 & 50.412 \\
\hline 4 & 0.572 & 1.3 & 1.8 & Core & 62.033 & 92.759 & 3.612 & 10.837 & 36.123 & 122.82 \\
\hline 5 & 0.501 & 1 & 1.4 & Core & 371.14 & 252.675 & 14.786 & 29.572 & 33.268 & 147.86 \\
\hline 6 & 0.392 & 1.5 & 2 & Ncore & 26.766 & 54.809 & 4.811 & 4.811 & 8.019 & 14.434 \\
\hline 7 & 0.496 & 1.4 & 1.9 & Ncore & 33.852 & 45.533 & 6.151 & 15.378 & 18.453 & - \\
\hline 8 & 0.527 & 1.4 & 1.9 & Ncore & 40.567 & 58.630 & 12.239 & 21.419 & 30.599 & - \\
\hline 9 & 0.539 & 1 & 1.3 & Core & 72.726 & 60.119 & 11.861 & 32.620 & 47.447 & - \\
\hline 10 & 0.459 & 1.2 & 1.7 & Core & 225.12 & 207.07 & 17.270 & 31.662 & 69.082 & - \\
\hline 11 & 0.499 & 1.4 & 1.9 & Ncore & 32.911 & 45.728 & 6.137 & 15.342 & 18.411 & - \\
\hline 12 & 0.662 & 1.3 & 1.7 & Ncore & 59.967 & 71.304 & 29.755 & 59.511 & - & - \\
\hline 13 & 0.679 & 1 & 1.2 & Core & 228.07 & 159.00 & 74.796 & 179.51 & - & - \\
\hline 14 & 0.535 & 1.2 & 1.5 & Core & 440.47 & 309.88 & 89.843 & 279.51 & - & - \\
\hline 15 & 0.336 & 1.1 & 1.2 & Core & 396.85 & 99.96 & 49.756 & 99.512 & - & - \\
\hline 16 & 0.623 & 1.2 & 1.4 & Ncore & 182.88 & 149.55 & 79.739 & 149.51 & - & - \\
\hline 17 & - & - & - & Ncore & 350 & - & - & - & - & - \\
\hline 18 & - & - & - & Ncore & 550 & - & - & - & - & - \\
\hline 19 & - & - & - & Core & 800 & - & - & - & - & - \\
\hline 20 & - & - & - & Core & 1150 & - & - & - & - & - \\
\hline
\end{tabular}

Table 6

OptFolio vs OL

\begin{tabular}{ll}
\hline & Optimal portfolio (drugs selected) \\
\hline $\begin{array}{l}\text { OptFolio model } \\
\text { OptFolio light (OL) model }\end{array}$ & 15,20 \\
\hline
\end{tabular}

model results seem to satisfy this desire: 11 drugs are selected, with four allocated in the latter stages (FDA) of the process and seven placed in the early stages (clinical phase). Moreover, the most valuable drugs $(5,14,15,19)$, which are allocated within the core therapeutic area (drug 16 excepted), are selected in-house, while alliances are allocated drugs which are in different stages of the development process and are in core $(3,4,10)$ and non-core therapeutic areas $(2,6,7)$, in order to exploit the complementary skills of the biotech company (Bianchi et al., 2011). Comparing Table 6 with Table 7, we can observe that OI makes an important contribution to the value of the chosen portfolio: In fact, the most
Table 7

The optimal portfolio composition and the overall ROV (OOL model).

\begin{tabular}{lllll}
\hline $\begin{array}{l}\text { Drugs } \\
\text { selected }\end{array}$ & In alliance & In-house & $\begin{array}{l}\text { Supporting } \\
\text { drugs }\end{array}$ & ROV (M\$) \\
\hline 11 & $2,3,4,6,7,10$ & $5,14,15,16,19$ & 0 & $\begin{array}{l}\text { M\$ } \\
2213.74\end{array}$ \\
\end{tabular}

valuable drugs $(5,14,15,16,19)$ continue to be chosen in-house, in order to maintain their total ownership $\left(\alpha_{i}=100 \%\right)$, and six potentially valuable drugs are selected in alliance, causing an overall increase of ROV. This result is very important in terms of risk held by the pharmaceutical industry: Drugs that are in the early stages of the process (and are thus characterized by higher uncertainty) and will not necessarily come to market, are chosen in alliance; so the pharmaceutical company shares the risk with the biotech company. Moreover, this confirms that firms have a greater propensity to initiate equity alliances under high uncertainty (Folta, 1998). 
Table 8

The optimal portfolio composition and the overall ROV with a more stringent budget.

\begin{tabular}{|c|c|c|c|c|c|c|}
\hline & $\begin{array}{l}\text { No. of } \\
\text { drugs } \\
\text { selected }\end{array}$ & $\begin{array}{l}\text { In } \\
\text { alliance }\end{array}$ & $\begin{array}{l}\text { In- } \\
\text { house }\end{array}$ & $\begin{array}{l}\text { Supporting } \\
\text { drugs }\end{array}$ & R\&D share & $\begin{array}{l}\text { ROV } \\
\text { (M\$) }\end{array}$ \\
\hline OOL model & 6 & $2,6,10$ & $\begin{array}{l}5,15, \\
20\end{array}$ & 15,20 & $\begin{array}{l}15=89.29 \% \\
20=1.9 \%\end{array}$ & 1730.12 \\
\hline OL model & 4 & - & $\begin{array}{l}5,10 \\
15,20\end{array}$ & 15,20 & $\begin{array}{l}15=37.29 \% \\
20=3.44 \%\end{array}$ & 1650.87 \\
\hline
\end{tabular}

Table 8 shows the results of optimal portfolio selected when, ceteris paribus, budget constraints are more stringent $(\mathrm{M} \$ 400$ for the first year and M\$ 100 for the remaining ones).

This numerical example highlights even more benefits from the adoption of open innovation. In fact, the most valuable drugs $(5,15,20)$ continue to be chosen in-house, and are all placed in core therapeutic areas, while drug 10 is chosen in alliance (even if $C_{10}^{\prime}<C_{10}$, because the alliance allows some budget to be freed up and thus allocated to other products), and two new products $(2,6)$ are selected in alliance and placed in non-core therapeutic areas, causing an overall increase of ROV. So, open innovation contributes in a twofold way: in primis it makes the optimal portfolio more balanced (drugs which are in different stages of the process are selected) and more diversified (drugs are in both core and non-core areas), and on the other side, drugs that are less likely to be launched on the market are chosen in alliance, thereby reducing the risk for the pharmaceutical company. For these products, in fact, the risk is shared with the biotech company.

In particular, as suggested by Rogers et al. (2002), drugs 15 and 20 are selected in both scenarios because they have a very large $V_{0 i}$ and a high chance of being successfully launched on the market, compared to the other potential drugs; these two products in the study of Rogers et al. (2002) show a robustness compared to the budgetary constraints (they are always chosen when the budget varies).

Finally, an important contribution is provided by the possibility of self-financing of the drugs selected. It is indeed worth noting that if this problem had been solved with the same budget constraints, but without any chances of self-financing, it would have led to a lower overall ROV, which is equal to M\$ $1.515,49$ (see Table 9): The ROV decreases and less profitable drugs are selected - i.e. 7 and 11 , rather than 5 . In fact, just the reinvested market revenues of drugs 15 and 20 would allow for the development of the profitable drug 5 , leading to a higher portfolio ROV.

\section{Discussions and conclusions}

This paper addresses an issue that is related to three literature streams: open innovation, real options analysis, and R\&D portfolio selection. R\&D portfolio selection, especially in some industries, cannot avoid taking into consideration the OI alternative, and in the meanwhile dealing with the intrinsic uncertain and flexible nature of the process. As a result, the ROA method becomes a must in this field. The managers perceive ROA adoption as a complex task, so they prefer to use a simple and easily manipulated means by which to evaluate investments (NPV most of all). Our main contribution to the literature is to propose a closedform model that is easy to implement (but not to manipulate) in order to select which R\&D projects to finance and how to carry them out-that is, developing them in-house or with an alliance that represents an operative way to deploy OI. Our model,
Table 9

The optimal portfolio composition and the overall ROV without self-financing.

\begin{tabular}{lllll}
\hline & $\begin{array}{l}\text { No. drugs } \\
\text { selected }\end{array}$ & In alliance & $\begin{array}{l}\text { In- } \\
\text { house }\end{array}$ & $\begin{array}{l}\text { ROV } \\
\text { (M\$) }\end{array}$ \\
\hline $\begin{array}{l}\text { OOL without self-financing } \\
\text { model }\end{array}$ & 7 & $\begin{array}{l}2,6,7,10, \\
11\end{array}$ & 15,20 & 1515.49 \\
\hline
\end{tabular}

moreover, considers the self-financing option: Every portfolio should be composed of elements able to produce cash flows and others that need financial support; usually, these will finance new entries into the portfolio (according to the life cycle of the element). The biopharmaceutical industry is characterized by a long, uncertain, expensive, and strategic R\&D function, which thus represents an ideal benchmark for our model, even though it can be customized according to the industry considered. In the developed biopharmaceutical numerical example, each potential drug that reaches the market has an implicit option consisting of financing drugs in the pipeline, and this option cannot be taken into consideration without a portfolio perspective. Finally, we propose selecting the portfolio assuming a strategic perspective: Actually, the R\&D decisions have a significant impact on the firm's future performances, so we believe that the firm's weaknesses and strengths should impact on these decisions. The proposed model takes this aspect into account through the core/non-core nature of the drugs. The results obtained for the developed numerical case suggest the selection of a multi-balanced portfolio: This is composed of drugs of different types (that are at different stages of the pipeline), which are developed both inhouse and in alliance; thus, the model gives the best mix of closed-open innovation patterns in terms of risk control, and some of the selected drugs are able to self-finance the portfolio. The model can be easily extend to consider other kinds of open innovation solutions.

Further developments aim to test the model in other R\&Dbased industries; moreover, a sensitivity analysis allows the obtained results to be generalized in order to obtain further insight into the optimal selection of the R\&D portfolio from an inter-industry perspective. In addition, building on the findings of Vassolo et al. (2004), further developments aim to investigate the interactions between projects. Finally, the optimal timing to license has to be investigated by combining a game-theory perspective.

\section{References}

Black, F., Scholes, M., 1973. The pricing of options and corporate liabilities. Journal of Political Economy 81, 637-654.

Berzinsh, G., Nechval, N., Purgailis M., 2006. Optimal investment decisions for a set of projects under conditions of uncertainty. In: Proceedings of IEEE International Conference Industrial Technology. (ICIT 2006), pp. 911-916.

Bianchi, M., Cavaliere, A., Chiaroni, D., Frattini, F., Chiesa, V., 2011. Organisational modes for open innovation in the bio-pharmaceutical industry: an exploratory analysis. Technovation 31 (1), 22-33.

Bingham, A., Spradlin, D., 2011. The Open Innovation Marketplace: Creating Value in the Challenge Driven Enterprise. FT Press, New Jersey (US).

Bowman, E.H., Moskowitz, G.T., 2001. Real options analysis and strategic decision making. Organization Science, Informs 12 (6), 772-777.

Brach, M., Paxson, D., 2001. A gene to drug venture: Poisson options analysis. R\&D Management 31, 203-214.

Carlsson, C., Fullér, R., 2003. A fuzzy approach to real option valuation. Fuzzy Sets and Systems 139, 297-312.

Cassimon, D., Engelen, P.J., Thomassen, L., Van Wouwe, M., 2004. The valuation of a NDA using a 6-fold compound option. Research Policy 33, 41-51.

Cassimon, D., De Backer, M., Engelen, P.J., Van Wouwe, M., Yordanov, V., 2011a. Incorporating technical risk in compound real option models to value a pharmaceutical R\&D licensing opportunity. Research Policy 40, 1200-1216. 
Cassimon, D., Engelen, P.J., Yordanov, V., 2011b. Compound real option valuation with phase-specific volatility: a multi-phase mobile payments case study. Technovation 31, 240-255.

Chance, D., 1998. Essays in Derivatives. New Hope, PA: Frank J. Fabozzi Associates, 323.

Chesbrough, H., Crowther, A.K., 2006. Beyond high-tech: early adopters of open innovation in other industries. R\&D Management 36 (3), 229-236.

Chriss, N.A., 1997. Black-Scholes and Beyond, 496. McGraw-Hill, New York.

Cooper, R.G., Edgett, S.J., Kleinshmidt, E.J., 1997. Portfolio Management for New Products. McMaster University, Hamilton, ON.

Copeland, T., Antikarov, V., 2001. Real Options - A Practioner's Guide. Texere, New York.

Cox, J., Ross, S., Rubenstein, M., 1979. Option pricing: a simplified approach. Journal of Financial Economics 7, 229-264.

Dahlandera, L., Gannb, D.M., 2010. How open is innovation? Research Policy 39, 699-709.

Dhankhar, A., Evers, M., Møller, M., 2012. Escaping the sword of Damocles: toward a new future for pharmaceutical R\&D, McKinsey Perspectives on Drug and Device R\&D.

DiMasi, J., Hansen, R.W., Grabowski, H.G., 2003. The price of innovation: new estimates of drug development costs. Journal of Health Economics 22, 151-185.

Dixit, A., Pindyck, R., 1994. Investment under Uncertainty. Princeton University Press. Eilat, H., Golany, B., Shtub, A., 2006. Constructing and evaluating balanced portfolios of R\&Di projects with interactions: a DEA based methodology. European Journal of Operational Research 172, 1018-1039.

Enea, G., Lo Nigro, G., 2011a. An affordable way to implement real options to select optimal R\&D portfolio, 22nd Annual POMS Conference, Operations Management The Enabling Link, 29 April to May 2, Reno, NV.

Enea, G., Lo Nigro, G., 2011b. A real options based model to select a balanced R\&D portfolio, 15th Annual International Conference on Real Options, June 15-18, Turku.

Folta, T.B., 1998. Governance and uncertainty: the tradeoff between administrative control and commitment. Strategic Management Journal 19 (11), 1007-1028.

Geske, R., 1979. The valuation of compound options. Journal of Financial Economics 7, 63-81.

Gupta, A., Pawara, K.S., Smartb, P., 2007. New product development in the pharmaceutical and telecommunication industries: a comparative study. International Journal of Production Economics 106, 41-60.

Hartmann, M., Hassan, A., 2006. Application of real options analysis for pharmaceutical R\&D project valuation-empirical results from a survey. Research Policy 35, 343-354.

Hassanzadeh, F., Collan, M., Modarres, M., 2011. A technical note on "A fuzzy set approach for R\&D portfolio selection using a real options valuation model" by Wang and Hwang (2007). Omega 39, 464-465.

Kamien, M.I., Schwartz, N.L., 1978. Self-financing of an R\&D project. The American Economic Review 68 (3), 252-261.
Kellog, S., Charnes, J.M., 2000. Real options valuation for a biotechnology company. Financial Analyst Journal 56, 76-84

Lazzarotti, V., Manzini, F., Mari, L., 2011. A model for R\&D performance measurement. International Journal of Production Economics 134, 212-223.

Licthnthaler, U., 2011. Open innovation: past research, current debates and future directions. Academy of Management Perspective 25 (1), 75-93.

Loch, C.H., Bode-Greuel, K., 2001. Evaluating growth options as sources of value for pharmaceutical research projects. R\&D Management 31 (2), 231-248.

Lo Nigro, G., Enea, G., Morreale A., 2012a. Real Option Analysis (ROA) Opens Innovation: the biopharmaceutical case, in Grubbström, R.W., Hinteruhuber, H. (Eds.), Proceedings of the 17th International Working Seminar on Production Economics, February 20-24, Innsbruck.

Lo Nigro, G., Perrone, G., Chiapparrone, S., 2012b. Governance forms drivers in biopharmaceutical inter-firm relationships. International Journal of Production Economics 140, 604-613.

Merton, R.C., 1976. Option pricing when underlying stock returns are discontinuous. Journal of Financial Economics 3, 124-144.

Nicholson, S., Danzon, P.M., Mccolough, J., 2005. Biotech-pharmaceutical alliances as a signal of asset and firm quality. Journal of Business 78 (4), 1433-1464.

Pennings, E., Lint, O., 1997. The option value of advanced R\&D. European Journal of Operational Research 103, 83-94.

Pennings, E., Sereno, L., 2011. Evaluating pharmaceutical R\&D under technical and economic uncertainty. European Journal of Operational Research 212 (2), 374-385.

Perlitz, M., Peske, T., Schrank, R., 1999. Real options valuation: the new frontier in R\&D project evaluation? R\&D Management 29 (3), 255-270.

Rogers, M.J., Maranas, C.D., 2005. Valuation and design of pharmaceutical R\&D licensing deals. American Institute of Chemical Engineers Journal 51 (1), 198-209.

Rogers, M., Gupta, J., Maranas, C.D., 2002. Real options based analysis of optimal pharmaceutical research and development portfolios. Industrial and Engineering Chemistry Research 41, 6607-6620.

Sereno, L., 2010. Real Options Valuation of Pharmaceutical Patents: a Case Study (February 3, 2010). Available at: 〈http://ssrn.com/abstract=1547185 .

Shockley, R., Curtis, S., Jafari, J., Tibbs, K., 2003. The option value of an early-stage biotechnology investment. Journal of Applied Corporate Finance 15, 44-55.

Trigeorgis, L., 1996. Real Options: Managerial Flexibility and Strategy in Resource Allocation, MIT Press, Cambridge, MA.

Vanhaverbeke, W., Van de Vrande, V., Chesbrough, H., 2008. Understanding the advantages of open innovation practices in corporate venturing in terms of real options. Creativity and Innovation Managment 17, 251-258.

Vassolo, R.S., Anand, J., Folta, T.B., 2004. Non-additivity in portfolios of exploration activities: a real options-based analysis of equity alliances in biotechnology. Strategic Management Journal 25, 1045-1061.

Wang, J., Hwang, W.L., 2007. A fuzzy set approach for R\&D portfolio selection using a real options valuation model. Omega 35 (3), 247-257. 